\title{
Incorporating local foods into low-income families' home-cooking practices: The critical role of sustained economic subsidies
}

\author{
Jennifer E. Gaddis a * \\ University of Wisconsin-Madison
}

Amy K. Coplen b

Portland State University

Molly Clark-Barol c

University of Wisconsin-Madison

\author{
Allea Martin d \\ Kaiser Permanente Northwest Center for \\ Health Research \\ Claire K. Barrett ${ }^{\mathrm{e}}$ \\ University of Wisconsin-Madison \\ Lauren Lubowicki ${ }^{\mathrm{f}}$ \\ Friends of Zenger Farm
}

Submitted February 17, 2020 / Revised June 18 and September 14, 2020 / Accepted September 15, 2020 /

Published online November 17, 2020

Citation: Gaddis, J. E., Coplen, A. K., Clark-Barol, M., Martin, A., Barrett, C. K., \& Lubowicki, L. (2020).

Incorporating local foods into low-income families' home-cooking practices: The critical role of sustained economic subsidies. Journal of Agriculture, Food Systems, and Community Development, 10(1), 117-132.

https://doi.org/10.5304/jafscd.2020.101.019

Copyright (C) 2020 by the Authors. Published by the Lyson Center for Civic Agriculture and Food Systems. Open access under CC-BY license.

\section{Abstract}

Alternative food practices, including farmers markets and CSAs, are often inaccessible to low-

a $*$ Corresponding author: Jennifer E. Gaddis, Department of Civil Society and Community Studies; University of Wisconsin-Madison; 4251 Nancy Nicholas Hall, 1300 Linden Drive; Madison, WI 53706 USA; +1-608-265-3759; jgaddis@wisc.edu

b Amy K. Coplen, Toulan School of Urban Studies and Planning, Portland State University; P.O. Box 751; Portland, Oregon 97207 USA; akcoplen@gmail.com

${ }^{c}$ Molly Clark-Barol, Departments of Sociology and Civil Society and Community Studies, University of WisconsinMadison; 4150 Nancy Nicholas Hall, 1300 Linden Drive; Madison, WI 53706 USA; clarkbarol@wisc.edu

d Allea Martin, Kaiser Permanente Northwest Center for Health Research; 3800 North Interstate Avenue; Portland, OR 97227 USA; allea.martin@gmail.com

e Claire K. Barrett, Department of Civil Society and Community Studies, University of Wisconsin-Madison; 4252 Nancy Nicholas Hall, 1300 Linden Drive; Madison, WI 53706 USA; ckbarrett@wisc.edu income families. Subsidized CSAs and fruit and vegetable prescription programs have the potential to decrease food insecurity, increase fresh fruit and vegetable consumption, and generate better health outcomes. However, several challenges can limit

f Lauren Lubowicki, Friends of Zenger Farm; 11741 SE Foster Rd., Portland, OR 97266 USA; lauren@,zengerfarm.org

\section{Funding Disclosure}

Support for the 2018 CSA Partnerships for Health was provided by Kaiser Permanente's Healthy Eating Active Living Grants and Partnerships, Kaiser Permanente Special Initiative Grants, Providence Health and Services Grants and Sponsorships, OHSU Knight Cancer Institute Community Partnership Program, Community Food Project grant no. 2015-33800-24194/project accession no. 1006979 from the USDA National Institute of Food and Agriculture, Bob's Red Mill, and the Uber Northwest Community Impact Initiative. The Madison research was supported by the U. S. Department of Agriculture, National Institute of Food and Agriculture, Hatch grant WIS01925, and draws on the data collected for Claire Barrett's doctoral dissertation. 
the success of such programs, including the logistics of distribution and an inability to cook from scratch due to a lack of kitchen infrastructure, time, or skills. In this paper, we investigate two dietrelated health programs conducted with community partners in Madison, Wisconsin, and Portland, Oregon. We used photovoice to evaluate and enhance these programs, which supplied lowincome participants with free or subsidized weekly shares of local food, addressed transportation barriers associated with access, and offered recipes and cooking education. Drawing on social practice theory, we demonstrate how these programs altered food provisioning practices for low-income individuals and families by building their competence in the kitchen, fostering meaningful social relationships, and cultivating new meanings related to fresh, local food. The short-term gains were positive, and such community-based nutrition programs warrant continued support as part of a broader strategy to address poverty and food insecurity.

\section{Keywords}

Community-Based Participatory Research, Home Cooking, Community Nutrition Programs, Food Insecurity, Community Supported Agriculture, Local Food, Low-Income Families, Photovoice, Social Practice Theory

\section{Introduction and Literature Review}

Local food is often inaccessible to low-income consumers, many of whom lack the resources to

\footnotetext{
Disclosures

The two primary authors of this paper (Jennifer E. Gaddis and Amy K. Coplen) were directly involved in the data collection and analysis of these research projects, but not in the implementation of the programs analyzed in this paper. Molly Clark-Barol primarily supported data analysis and writing. Allea Martin and Claire K. Barrett were directly involved in both data collection and analysis and the implementation of the respective programs. Lauren Lubowicki was directly involved in the design and implementation of the Portland program as well as data collection. The authors have no conflicts of interest to disclose.
}

purchase higher-cost produce and/or the infrastructure to cook fresh vegetables. Subsidized CSAs ${ }^{1}$ have the potential to decrease food insecurity, increase consumption of fresh fruits and vegetables for adults and children, and generate better health outcomes (Bryce et al., 2017; Izumi et al., 2018; Landis et al., 2010; Ridberg, Merritt, Harris, Young, \& Tancredi, 2019; Wilkins, Farrell, \& Rangarajan, 2015). The growing popularity of local food has motivated new research on how to successfully incorporate CSAs into community-based nutrition programs (Cohen \& Derryck, 2011; McGuirt et al., 2018; Vasquez, Sherwood, Larson, \& Story, 2017) at a time when CSA farmers are facing increasing market competition (McKee, 2018) and declining consumer support (Trotter, 2018). However, several challenges can limit the success of such programs, including logistics of share pickup and uncertainty about how to prepare unfamiliar produce (Andreatta, Rhyne, \& Dery, 2008; Forbes \& Harmon 2008; McGuirt et al., 2019; Quandt, Dupuis, Fish, \& D'Agostino, 2013; White et al., 2018).

Furthermore, simply increasing physical access to local food is not enough to dramatically change long-term dietary behavior (Cummins, Flint, \& Matthews, 2014). Successful dietary programs must also address socio-cultural factors-including nutrition knowledge, cooking skills, attitudes, motivations, and social support—which affect dietary intake and engagement in farmers markets, CSAs, and other alternative food practices (Castellanos, Keller, \& Majchrzak, 2016; Farmer, Babb, Minard, \& Veldman, 2019). It is also important to acknowledge the ways in which efforts to bring "good food" to others often universalize white values and consumption practices as normative and superior and reduce structural inequality to cultural difference (Alkon, 2012; Guthman, 2011; Slocum, 2006). More research is therefore needed to understand and appreciate the diversity of experiences that individuals have when participating in subsidized CSA programs in order to identify design features that facilitate the adoption of new dietary practices. In this paper, we investigate two nutrition pro-

\footnotetext{
${ }^{1}$ Community supported agriculture (CSA) is a direct to consumer agriculture model. In its traditional form, members pay upfront for a season's worth of produce from a local farm and receive regular shares of produce.
} 
grams conducted with community partners in Madison, Wisconsin and Portland, Oregon. Both programs attended to the limitations of subsidized CSAs identified by Andreatta et al. (2008) and White et al. (2018) by addressing transportation barriers associated with pick-up and providing recipe ideas, cooking education, and/or slow cookers. The Madison program coupled pick-up with weekly classes that participants were already attending, and the Portland program offered free ride sharing to pick-up locations. All participants were low-income and the majority were women.

We analyze data from both programs to answer three primary research questions:

1. How does the introduction of new elements (i.e., local produce and slow cookers) shape participants' home-cooking practices?

2. How does the relationship that participants develop with producers and/or suppliers of local food shape their adoption of alternative food practices?

Figure 1. The Practice of Eating Local Vegetables

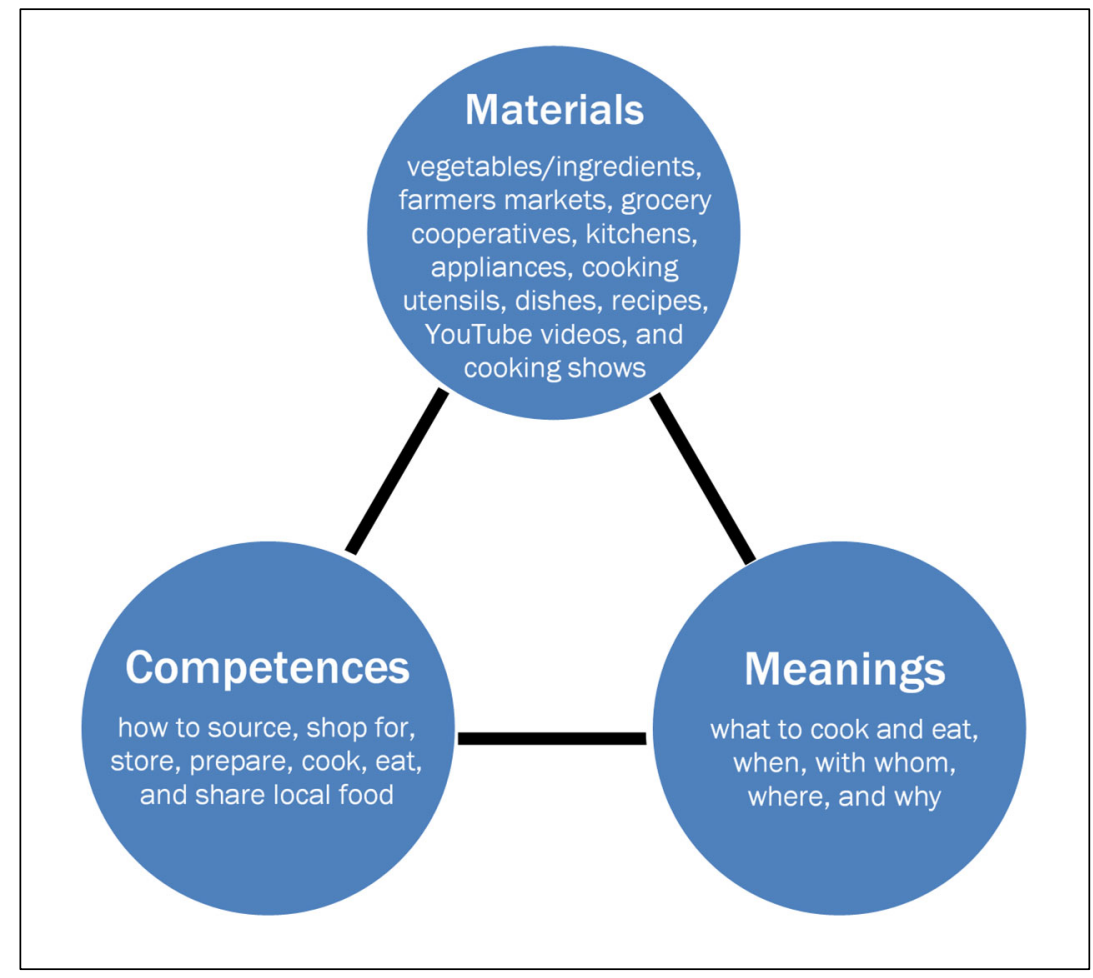

Source: Adapted from Maller, 2015.
3. What effect does the practice of sharing locally produced food and/or recipes with others have on participants' attitudes toward experimenting with unfamiliar foods and/or culinary techniques?

We use social practice theory (SPT) to investigate how the introduction of local food and slow cookers altered low-income individuals' food provisioning practices, thereby building on a growing body of SPT scholarship within food studies (Devaney \& Davies, 2017; Fonte, 2013; Kendall, Brennan, Seal, Ladha, \& Kuznesof, 2016; O’Neill, Clear, Friday, \& Hazas, 2019; Spaargaren, Oosterveer, \& Loeber, 2013; Torkkeli, Mäkelä, \& Niva, 2020; Tucker, 2019; Twine, 2015) and public health research (Delormier, Frohlich, \& Potvin, 2009; Maller, 2015). The term "social practice" refers to routinized behaviors made up of interconnected elements, including bodily and mental activities, things and their uses, know-how, and emotions (Reckwitz, 2002). Shove, Pantzar, and Watson (2012) define a practice as the product of three types of elements: (1) materials objects, tools, technologies, and infrastructures; (2) competenceskills and know-how; (3) meanings-norms, cultural conventions, and expectations. These elements shape how people perform practices, and vice versa (Mylan \& Southerton, 2018).

Social practices emerge, evolve, and disappear, transforming over time and mediating the relations between consumers, producers, and systems of provisioning (Southerton, Chappells, \& van Vliet, 2004; Spaargaren, 2003). For example, competences related to home gardening and food preservation-once widespread practices in the U.S.were largely displaced by the practice of purchasing frozen and/or canned vegetables from grocery stores, but have recently undergone a resurgence. Figure 1 
illustrates the materials, competence, and meanings associated with the practice of eating local vegetables.

While individual performances of practices can reproduce or re-shape those practices over time, practices are not isolated or individually constructed. Rather, they are "bundled" together and shaped by other practices, and embedded in social contexts. For example, recipients of Supplemental Nutrition Assistance Program (SNAP) benefits must navigate restrictions on what they can and cannot purchase. Low wages and low benefit amounts often push SNAP participants to purchase cheap high-caloric processed foods instead of fresh fruits and vegetables. However, some recent SNAP policies — such as "Double Up Food Bucks" at farmers markets-make it easier for lowincome families to purchase healthy local foods (Farmer, Babb, Minard, \& Veldman, 2019; Mann, O'Hara, Goddeeris, Pirog, \& Trumbell, 2018; Oberholtzer, Dimitri, \& Schumacher, 2012; Woodruff et al., 2018). This demonstrates the ways in which food provisioning and other social practices are embedded in the context of (and also shaped by) ever-changing social, political, and economic systems.

By employing SPT, we strategically shift the unit of analysis from the individuals who participated in community-based nutrition programs in Madison and Portland to the food-related practices they engaged in during the programs. Both programs sought to change outcomes (i.e., cooking and consumption practices) by deconstructing and re-configuring the elements within the bundled set of practices known as "food provisioning." In Madison, this involved introducing new materials (i.e., a slow cooker and regular deliveries of vegetables and other healthy foods), new competences related to home cooking with potentially unfamiliar ingredients (cultivated by sharing recipes and knowledge through in-person discussion and a private Facebook group), and new meanings (particularly in relation to locally and organically produced foods and different cultural cuisines). In Portland, the program introduced new materials (i.e., a weekly CSA share) and new competences (via cooking demonstrations, recipes, weekly newsletters, and other programmatic events), while forging new meanings related to local food and the environment through interactions with farm staff and other CSA members who participated in a subsidized CSA program.

By focusing our analysis on these two programs, rather than a single program alone, we are better able to explore the range of experiences that low-income individuals have when asked to adopt new practices as part of a community-based nutrition program emphasizing local food. These cases also allow us to investigate how the "interlocking practices" of shopping, storing, cooking, and eating food are related to broader everyday spatial and temporal rhythms (e.g., of work and childcare) so that we can identify novel strategies that promote health and sustainability (Southerton, DíazMéndez, \& Warde, 2012). Recognizing these practices as interlocking can, according to Southerton et al., redirect attention from ineffectual policies aimed at "persuading, influencing and encouraging attitudinal change in the hope that millions of people will simultaneously change their behaviours" (2012, p. 34) toward programs that address how daily practices are specifically reinforced and/or disrupted and then reconfigured in more healthy and sustainable ways.

\section{Research Methods}

After receiving IRB approval for both projects, we employed the community-based participatory research (CBPR) method photovoice to evaluate and enhance the subsidized CSA programs. Photovoice is a qualitative research method that enables participants to document and investigate their experiences through photography, discussion, and storytelling. Similar to other CBPR methods, photovoice is designed to elevate participants to the role of researchers, enabling them to build skills and cultivate relationships with fellow participants (Wang, Yi, Tao, \& Carovano, 1998). Photovoice moves beyond isolated concepts or indicators to investigate the lived collective experiences of participants (Balvanz et al., 2011). Public health practitioners have used photovoice to evaluate health promotion and intervention practices (Jurkowski \& Paul-Ward, 2007; Livingood et al., 2017; McMorrow \& Saksena, 2017; Wang, 1999) and food justice scholars promote it as a way to 
center the voices and needs of those experiencing food insecurity (Pine \& de Souza, 2013; Porter, 2018; Vernon, 2015; Woodsum, 2018).

While both projects used photovoice and provided subsidized deliveries of healthy and local foods to program participants, there are some notable differences in the two CBPR projects. In the following sections, we describe the logistics, photovoice protocols, data collection and analysis procedures for each of the two community-based nutrition programs.

\section{Madison Food Exploration Partnership}

The Odyssey Project-Slow Food UW partnership in Madison began in 2016 as a community-based nutrition education and research partnership between the Odyssey Project and the University of Wisconsin-Madison (UW) student-led chapter of Slow Food International, called Slow Food UWMadison (SFUW). Odyssey is an educational program run by the University of Wisconsin-Madison that offers a free humanities class and six college credits for adults living at or below the poverty level. Odyssey provides wraparound services for participants, including free textbooks, childcare and youth programming (facilitated, in part, by undergraduate SFUW volunteer interns), and a weekly dinner held during class. The SFUW interns participated in a weekly for-credit course in which they read articles related to food justice, including Julie Guthman's writing on the problematic nature of undergraduate students "bringing good food to others" (Guthman, 2008), and discussed strategies for engaging Odyssey participants in all aspects of the community-based nutrition project.

During the summer of 2016, one of the authors organized a focus group of former Odyssey students in which participants identified slow cookers as a culinary tool that could reduce time constraints on cooking from scratch. Thus, at the start of each academic year (2016-17 and 201718), all Odyssey students (30 each year) received a slow cooker. Only 12 adult participants, from a cohort of 30 returning adult-students, signed up during year one (2016-17) of the program. The Odyssey director requested that program recruitment procedures be altered for year two of the program (2017-2018) to allow students to join the study mid-project; however, no additional Odyssey students elected to join the program after it began. Across both academic year cohorts, 24 Odyssey students participated in this community-based nutrition program and were offered a modest incentive-a US $\$ 25$ phone credit or farmers market gift certificate-for completing all components of the research study.

Participants received 10 to 12 free deliveries of groceries valued at US\$16 each as an incentive to join the food exploration program. Thematic "food explorations" (e.g., fall harvest, Native foods, winter soups) included recipes utilizing the groceries as ingredients. SFUW undergraduate interns assembled food explorations by sourcing ingredients-fresh produce (often locally sourced and/or organic), grains/legumes, and some meat/ dairy-from farmers markets, a local butcher, a cooperative grocery store, and several ethnic markets. They also sourced some nonseasonal produce from conventional and discount grocers in an attempt to balance the project aims with program participant requests for specific ingredients. Notably, this method of sourcing and delivering the foods was a workaround that the SFUW interns developed in collaboration with their graduate student mentor. Initially, Growing Power, a Milwaukee-based nonprofit organization, was intended to supply market baskets for the program, but they stopped delivery to Madison between the writing of the U.S. Department of Agriculture (USDA) Hatch grant proposal to fund the program and implementing the program over a year later.

Deliveries were weekly for the first year of the program and switched to biweekly for the second year, based on participant feedback indicating that it would be easier to use the supplied ingredients if the deliveries were less frequent. On delivery days, a member of the research team, SFUW interns, and participants spent approximately 20 minutes discussing the contents of the food exploration, the theme, and the recipes in addition to debriefing the previous food exploration. Between in-person meetings, participants shared home-cooking triumphs and challenges via a private Facebook group. They were instructed to post at least three photos per food exploration of themselves and their families using the provided food items and 
were invited to post recipe ideas and questions for the group.

When reviewing photos from the first year of the program, we found that participants most often shared pictures of the finished meals they prepared, as opposed to also sharing pictures of how or with whom they prepared the meals. Consequently, the SFUW interns developed a more specific photovoice protocol, the "3P," for year-two participants in order to encourage them to take a variety of photos that could generate different types of insights into the home food environment. The 3P consisted of the people involved in the process of food preparation or consumption, the processes involved in preparing the foods, and the final products created (Figure 2).

The SFUW interns reminded participants about the 3P during the grocery deliveries and through periodic communication on the private Facebook group, producing a wider range of photos across the three categories. This paper reports on data from pre- and post-interviews (lasting 27-60 minutes), photos and captions shared in the Facebook group, and notes from weekly in-person participant discussions of the food explorations.

Pre- and post-interview questions focused on how participants learned to prefer and prepare different types of foods; the practices they engaged in to plan, procure, prepare, and consume meals at home; and a measure of participants" "food agency" (Trubek, Carabello, Morgan, \& Lahne, 2017). Food agency is a conceptual framework that places people and their food practices within a broader social and environmental context by examining the extent to which people are empowered to access and prepare food in ways that align with their goals, needs, and beliefs. Post interviews also included questions about their experiences in the program, such as the use of specific ingredients and anticipated changes in household food provisioning practices. The research team also used a compiled set of each participant's Facebook photos, captions, and comments to generate specific prompts for the post interviews. Each participant's recorded and transcribed interviews (pre/post) were then analyzed in Dedoose, an online qualitative analysis software tool, using a deductive coding scheme created through thematic analysis of the first-year interview transcripts and

\section{Figure 2. Participant Facebook Post Illustrating the 3P Photovoice Protocol Used by the Madison SFUW-Odyssey Project Partnership}

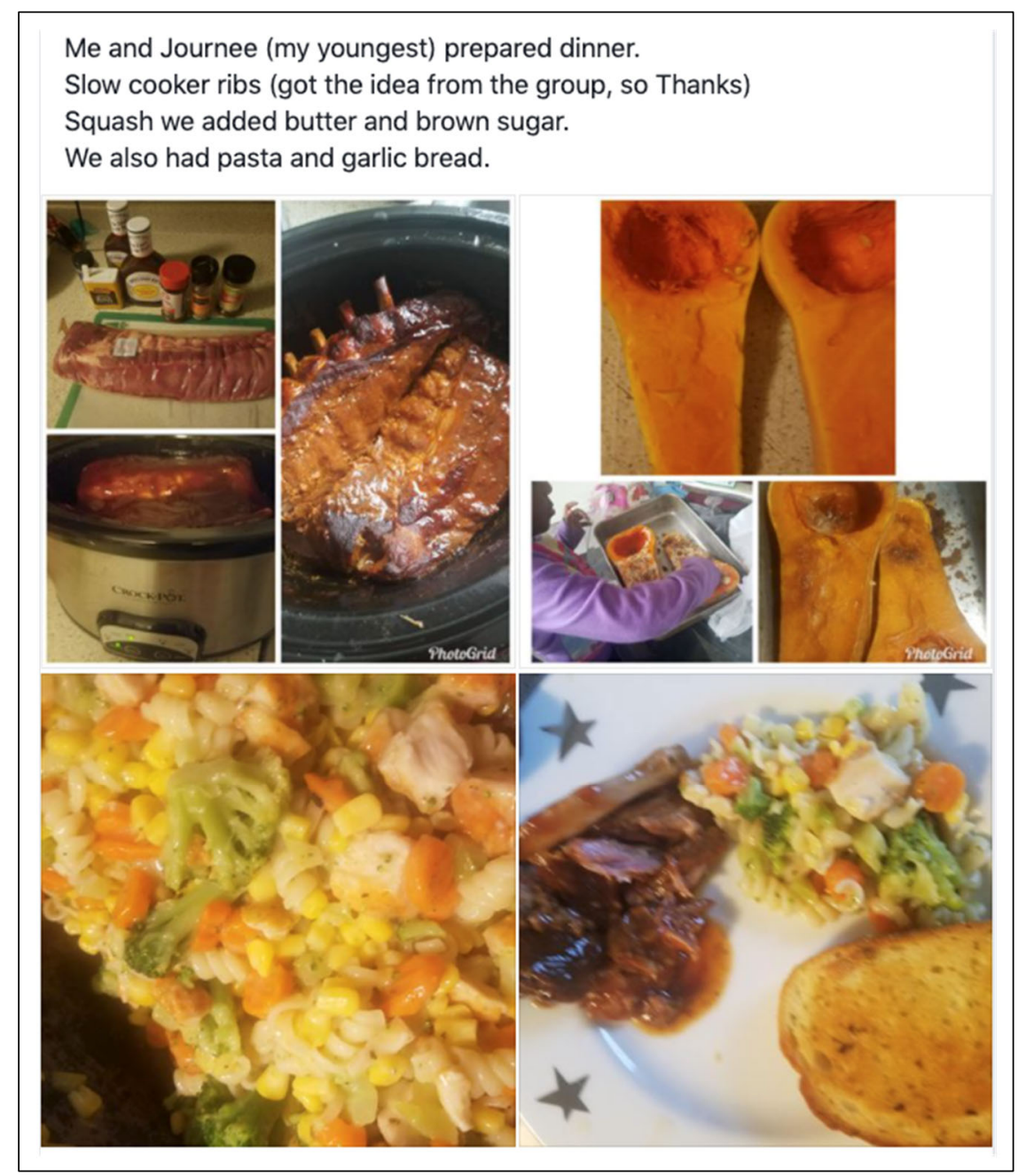


the food agency framework, with modifications suggested by Morgan (2020) that enhance the framework in ways that better account for the structural barriers impacting low-income communities of color and the food-related aspirations, constraints, and strategies that influence their food agency.

\section{Portland CS A Partnerships for Health}

In Portland, CSA Partnerships for Health $(\mathrm{CSAP} 4 \mathrm{H})$ is a subsidized program aimed at improving food security, diet quality, and overall health and well-being (Izumi et al., in press). This ongoing program was launched in 2015 as a CBPR partnership between federally qualified health centers, local farms, and academic institutions. Participants are recruited by community health workers (CHWs) at the health centers and pick up their CSA shares weekly for 18 to 22 weeks. Participants pay US $\$ 5$ per week using cash or SNAP benefits for a grant-subsidized share of locally grown produce valued at US\$27. In 2018, the year of the photovoice evaluation project, five local farms and nine health centers collaborated to provide shares to 251 households.

At pick-up, participants select quantities of available produce and interact with farm staff and CHWs. The program aims to increase social support by providing nutrition and cooking education and other programmatic events (Izumi et al., in press). The program-provided nutrition education includes weekly newsletters with skill sheets with written and visual instructions for preparing vegetables, recipes for cooking with the week's share, and stories from the farmers who supply the produce. Programmatic events include monthly inperson cooking demonstrations and tastings and occasional classes and events, such as a pizzamaking party hosted by one of the farms.

CSAP4H faces challenges common among diet-related health programs, including funding, attrition, and staff capacity. Grant funding cycles do not always align with the timing of CSA member sign-ups for the partner farms, and funding levels are uncertain and fluctuate significantly from year to year. These issues cause stress for those running the program and for farmers who might not be notified that funding was secured until just before the CSA season begins. CSAP4H is working to convince insurance companies to fund the program in future years, which would provide security and stability. In order to address high rates of attrition in the early years, CSAP4H secured funding from UBER to offer free rides to and from pick up, which significantly reduced attrition in later years. However, the issue of staff capacity remains unresolved, as the success of the program leans heavily on CHWs who already have a heavy workload at their respective clinics. Since the program began in 2015, CSAP4H partners have conducted research to identify challenges and evaluate the program.

We designed the 2018 photovoice project to augment findings from previous survey and focus group research (Martin, Coplen, Lubowicki, \& Izumi, 2020) in order to further evaluate the impact of CSAP4H on food security, diet quality, and overall health and well-being. We recruited 28 photovoice participants during weekly vegetable pick-ups at two locations, one in its first year of participating in the program and the other in its fourth year, into three groups, two Englishspeaking and one Spanish-speaking. CSAP4H facilitators did not instruct program participants to use the 3P protocol used by the Odyssey ProjectSlow Food UW partnership program. Instead, each focus group attended a 2-hour training session and had 3-4 weeks to take photos in response to the prompt: "How does this CSA program impact your life?" We downloaded and printed participants' photos for the focus groups. For each training and focus group, participants were offered transportation, childcare, and food. Participants also received a total of US $\$ 75$ in cash, prints of their photos, and digital cameras (about a US\$30 value).

During each focus group, participants selected up to five photographs and worked together using group dialog and consensus to organize them into three to five themes. These group-generated themes differed among focus groups, but included topics such as "growing," "cooking," "nutritional needs," and "community." We then facilitated a discussion using an abbreviated SHOWeD method (Wang, 1999): (1) What do we See here?, (2) What is really Happening here? (What is the story behind this photo?), (3) How does this relate to Our 
experience with CSA Partnerships for Health? Using these guiding questions, we asked participants to take turns sharing stories related to each theme and discuss how the photos they took captured their experience in CSAP4H. We then helped participants create captions for two of their photos, which we later displayed in printed booklets and on large banners at a public reception open to participants and their families, program staff, policymakers, and funders. The three focus groups were audio recorded, and the discussions were transcribed verbatim, translated in the case of the Spanish group, and uploaded to Dedoose. We used applied thematic analysis to code the focus group data and organize it into themes and sub-themes.

\section{Combined Case Analysis}

After the project-specific data described above was collected and analyzed by each respective CBPR team, members of the Madison and Portland research teams compared the results of the qualitative coding processes (both conducted in the Dedoose online data analysis platform) and identified three overarching themes that were present in both cases: (1) introducing materials, building competences, and shifting food practices, (2) impact of supplier relationships on the adoption of alternative food practices, (3) sharing food and recipes. In the following sections, we provide summary data and illustrative quotes related to each of these themes and discuss our findings using the social practice theory framework presented in Figure 1. We then outline the limitations of this study and make recommendations for future policy, practice, and research.

\section{Results}

\section{Introducing Materials, Building Competences, and Shifting Food Practices}

Both community-based nutrition partnerships reshaped food provisioning practices by introducing new materials and building (or renewing) participants' capacity and/or competence to cook healthy meals. For some participants, cooking from scratch with fresh vegetables was a new experience, while others had a much higher degree of competence and were inspired to draw on and revive recipes and from-scratch cooking practices which they had learned from their parents and/or grandparents.

The programs also encouraged and enabled participants to learn how to prepare unfamiliar produce and helped them cultivate new tastes.

Participants in both programs were provided with a variety of free or low-cost local produce and/or protein items that they identified as fresher, tastier, more visually appealing, and even more aromatic than what they could otherwise find and/ or afford in the grocery store. One Madison participant, for example, discussed how having an "abundance" of fresh vegetables allowed her to add more taste and flavor to her meals. Portland participants discussed learning about multiple varieties of eggplant and different parts of plants that they previously did not know were edible. One participant who reported being "raised on McDonald's and KFC" and not eating fresh vegetables as a child said, "You guys taught me how to eat the leaves of the beets. I didn't know that [before the program]. I threw that stuff away."

Madison participants emphasized how their program enabled them to both stretch their food budgets and substitute conventional ingredients with healthier, local, and organic ingredients. Many engaged in complex food provisioning practices (e.g., traveling to different stores in search of the best prices, clipping coupons, buying in bulk, freezing large quantities of food purchased at discount prices) and described their food exploration deliveries as supplementing or replacing these other practices. Participants who experienced a higher degree of food insecurity described the deliveries as a more significant element of the "bundle" of practices that they used to procure sufficient food for their families. "I appreciated it because we were going through hard times," one participant reported, "I didn't have any food stamps or anything. It was just one income in my house." This tough financial situation made it especially important for the participant to "use whatever" was in the food exploration. Madison participants noted that their ability to incorporate the items into their home cooking practices at no cost to their household budgets made culinary experimentation more enjoyable. Consistent with previous research (Clark-Barol, Gaddis, \& Barrett, 2021), the 
financial subsidy the programs offered lessened the risk that a recipe might not turn out correctly, be rejected by children, or otherwise end up in the garbage. This was especially true for participants who did not have much confidence in cooking meals from scratch.

In addition to free local produce and protein, the Odyssey-SFUW partnership introduced another material element into participants' home provisioning practices: a free 6-quart slow cooker. When viewed through the lens of SPT, slow cookers are a "de-skilling" technology that alters the relationship between the three elements of practice (materials, competences, and meanings) by folding competences (e.g., temperature regulation and cooking time) into the material element of the cooking technology itself. Our data confirms this insofar as participants consistently referenced how easy it was to prepare meals with the slow cooker. "I would cut up my vegetables at nighttime, season my meat, put it in the refrigerator, in the morning, add the juice, turn it on, and then by the time I got off work it was time to eat," explained one participant. In addition to the temporal convenience of slow cookers, the comparative user-friendliness and safety of the slow cooker enabled children to participate more actively in the practices of homecooking, because it alleviated parents' fears that young children might mishandle a crucial, timesensitive step in the cooking process or hurt themselves on an open flame. The slow cooker was not entirely a "deskilling" device, however, since it required those who were unfamiliar with the practice to develop and incorporate new temporal competences into their cooking routines (e.g., how and when to set up, add ingredients, and check the recipe). Moreover, several participants lacked functional kitchens with stoves and ovens, and the introduction of a slow cooker created new possibilities for preparing home-cooked meals.

The incorporation of new material elements and the expanded use of existing materials transformed participants' tastes. In Portland, for example, some participants recalled strongly disliking vegetables before the program, but reported that cooking from scratch made vegetables more appealing. Due to the CSA nature of their program, Portland participants expressed appreciation for the local vegetables produced by small farmers, which they identified as "more natural" and "much more appealing" than their "industrial" and "packaged" counterparts. The program changed some participants' expectations of what vegetables should look like, opening them up to (and even encouraging them to welcome) the imperfections of their locally sourced produce. Before joining the program, noted one participant, "I'd be like 'ew, this carrot has dirt on it, I don't want this. Where's my cute little shaved little bite-sized carrots?' . . . With this [program] I think I've eaten a lot more stuff I'd never even thought about eating." Participants also learned about seasonality, becoming, according to one participant, "more clued in to the way that our climate works and what things bloom when and locally, in this farm area." Having the opportunity to see vegetables in their "natural habitats," as one Portland participant phrased it, inspired some to adjust their home-cooking practices in order to consume more "natural" and "real" food in place of the "fake" versions purchased outside of the home. "I had [eggplant parmesan] at Olive Garden and theirs is all processed. It was all soggy," noted one participant, "So I really want to try [to cook it]." Likewise, in Madison participants expressed their desire to continue eating fresh, locally grown vegetables instead of frozen and canned vegetables, because they discovered how much better tasting they are, but noted that their income constraints would make this unlikely.

\section{Impact of Supplier Relationships on the Adoption of Alternative Food Practices}

Participants in both programs expressed appreciation for and developed relationships with the interns, CHWs, and farmers who managed, supported, and supplied their programs. While Madison participants learned how to cook unfamiliar foods from the SFUW interns and each other during in-person meetings and through the Facebook group, Portland participants took home useful recipes (sometimes with prepared samples) and learned how to prepare unfamiliar produce from farmers and CHWs at their farm stand pickup. Some Portland participants presented photos of CHWs and farmers during photovoice focus groups, illuminating the critical role these actors 
played in the program. "They're so happy and friendly and informative every week," reflected one participant on her photo of a CHW. "Without them, the program wouldn't [exist]." A Madison participant expressed a similar positive opinion of the interns: "I really like that the interns are so friendly and I think that means a lot, because then it makes us feel open to telling them if we-some recipe went wrong or something." However, some Madison participants indicated a cultural divide between themselves - many of whom were immigrants and people of color-and the interns, who were predominantly white, middle-class undergraduates, and communicated a desire for people more like themselves (i.e., low-income immigrants and people of color) to provide the food exploration deliveries.

Portland CSAP4H participants benefited from the opportunity to develop relationships with the local farm staff and interns who grow their food, a finding discussed in previous research on the program (Martin et al., 2020). While farmers did not reflect the overall demographics of participants in terms of race and ethnicity, they succeeded in connecting to participants in meaningful ways. Weekly interaction with farmers ranged from simple conversations about which seasonal, local vegetables were available that week to how unfamiliar vegetables taste and options for preparing them.

Portland parents reported that their children cultivated relationships with farmers, which changed their families' relationship to food. One participant discussed the role that farmers play for her son: "The farmers are truly like our family.... It makes me cry because he doesn't have that-our family isn't a bigger family_ and so ... with his special needs, he doesn't have a lot of community connection, but the farm is his farm." Participants and their children were also more willing to try unfamiliar vegetables because of their relationship with the farmers. One participant reflected on this phenomenon: "It's given us an opportunity to have [my son] try new things that he wouldn't necessarily try." Her son, who is an avowed tomatohater, bit into a purple tomato that his farmer handed to him and "he absolutely loved it."

Participants also expressed deep respect for the hard work of farmers. "I can't imagine how much work it must be just to not only be planting," noted one participant whose disability prohibits her from gardening, "but to harvest them ... [and] transport all those vegetables to [the health clinic] where we go pick them up." Another participant explained how her son's relationship to "his farmer" gives him "a different appreciation for food and a different appreciation for the work that goes into it ... that it's not just the factories or machines that make [our] food, [but] there's people behind it."

Forming relationships with farmers deepened Portland participants' connection to and appreciation for the natural systems that support local food production. The photovoice project itself-which was hosted on one of the farms that supplies the CSA—allowed participants to explore the setting where their food was grown. One participant reflected on her observation of farming practices during this experience: "The farmer has tried really hard to also be friendly to wildlife-planting certain kinds of plants next to the rows of the vegetables that the bugs are also attracted to. It's more of a natural kind of trying to keep the pests away." This participant gained a new understanding of her CSA as the product of a local farmer working in relationship with nature. In doing so, she assigned new meaning to local food, which helped her distinguish the practice of eating CSA vegetables from the practice of eating conventionally farmed vegetables.

\section{Sharing Food and Recipes}

Participants discussed the important role that food plays in their families and communities, especially as a tool for expressing love and fostering connection. The Odyssey-SFUW and CSAP4H programs offered participants an opportunity not only to access healthy food for themselves and their immediate families, but also share food and recipes with fellow participants, extended family, and neighbors. Participants reported that this deepened their relationships, describing with fondness how they engaged in cooking as a practice of socializing, caretaking, and meaning-making. One Portland participant noted that before she entered the program cooking "was not my favorite thing to do," but since she began spending time cooking with her son, "I love it." Similarly, a Madison 
participant identified one of the most meaningful outcomes of the Odyssey-SFUW partnership as "the connection I've made with my significant other." Likewise, a Portland participant who joined the program with her mother describes how the program offered them a way to spend quality time together: "Our schedules are always opposite, but with this program, on her days off, rather than just not really doing anything or hanging out or whatever, we always make it a point now to try to cook together."

Participants in both programs found joy in cooking fresh, healthy meals for their family, friends, and neighbors as a form of caretaking. A Madison participant expressed pride in using her slow cooker to prepare "good food" for her sons to eat while she was at work, while a Portland participant who works as a caregiver enjoyed using her CSA to make meals for the families of children in palliative care and hospice. Sharing a series of photos she took of different meals she prepared with a giant zucchini from her CSA, she noted, "it's not just about me. I get to share that the farm produced this vegetable. It didn't just come from a supermarket."

In Madison, participants belonged to a cohort, which facilitated peer-to-peer sharing. The practice of sharing with their adult classmates via short inperson discussions and through photos and videos, captions, and comments on the private Facebook group gave participants a window into their peers' home cooking practices, increasing their desire to try unfamiliar foods, recipes, and culinary techniques. In post-interviews, many participants commented on this dynamic and the excitement they shared when food exploration baskets were delivered to their classroom. "I felt like all of us were kind of on the same mission to just use the ingredients that were there," one participant explained. "So, there was some solidarity inside of all that, but you could see just everybody had their own kind of twist on that stuff," he continued, before describing how the photos and recipes fellow participants shared in the Facebook group helped inspire changes to his own home-cooking practices. These examples demonstrate the capacity for the cohort model to develop "communities of practice" (O’Neill et al., 2019) that enable participants to forge new social ties that facilitate adopting alternative food practices.

Notably, the Odyssey-SFUW partnership, which was situated within the practice of adult education, created opportunities for cross-cultural learning that transformed a broad range of participants' meanings around food. Many participants identified the practices of cooking with others and sharing stories as the most valuable components of the program. They especially appreciated learning about their classmates' home-cooking practices because it helped them understand the cultural backgrounds of their fellow learners, while imbuing the food exploration deliveries with new meanings and introducing potential culinary skills and techniques to test out in their own kitchens. "It's really awesome to just be able to accept and embrace different nationalities, different ethnicity groups, and learn from them," one participant explained. Another was impressed by the photos shared on Facebook. While she would "make just your standard Americana-type stuff," her peers would make soul food, vegetarian food, and Hmong food. "[Hmong food] looks pretty tasty," she said, "I would try to do that ... and sometimes I wonder about eating vegetarian." As these examples demonstrate, the practices of preparing and sharing home-cooked food with others-including dishes that incorporated unfamiliar foods or relied on new culinary techniques - transformed participants' relationships to food.

\section{Discussion and Conclusion}

Community-based nutrition programs in Portland and Madison impacted food provisioning practices for low-income individuals and families by introducing new material elements (i.e., food exploration deliveries, CSA shares, and slow cookers) and programming that elicited new competences and meaning-making in relation to cooking locally sourced food at home. These programs built participants' food-related competences, cultivated relationships between fellow participants and farmers/ suppliers of local food, and increased consumption of healthy, locally produced foods. Our findings are consistent with research by Andreatta et al. (2008) on a subsidized CSA program in North Carolina, which found that participants experi- 
mented productively with new recipes, shared meals with family and friends, and forged meaningful relationships with farmers and volunteers.

It is important for such programs to continue, even when restrictions on face-to-face gatherings are in place, as with the COVID-19 pandemic. The private Facebook group and $3 \mathrm{P}$ photovoice protocol used by the Madison SFUW-Odyssey Program partnership offers one promising way for nutrition educators and others who provide communitybased nutrition programming to continue to engage groups of participants in new social practices when face-to-face meetings are not possible. The photovoice focus groups in Portland and the interviews and Facebook group in Madison gave participants a place and time to articulate how these programs shaped their food practices, and to reflect on the meanings they attach to food and cooking. Through photovoice, we gained a personal, intimate, and embedded picture of the reconfiguration of practices within participants' home kitchens. By encouraging participants to take photos and interpret them through captions and conversation, we learned how they bundled certain practices together and how these bundled practices then became routinized into "complexes" (Shove et al., 2012) of behaviors that are regularly repeated. For example, participants framed budgeting as inseparable from food provisioning, and participants with children described their food-related practices in relation to parenting.

Based on our findings, we recommend that practitioners and policymakers utilize the insights of SPT to design more effective nutrition programs that not only lower barriers of accessibility and affordability, but also address the "complex architecture of factors" (i.e., cultural norms and habits, social and economic policies, and systems of provisioning) that impede adopting healthier and more sustainable diets (Devaney \& Davies, 2017, p. 825). Our research demonstrates that offering useful cooking equipment, technologies, recipes, lessons, and other materials and competences helps facilitate the adoption of alternative food practices.

We also suggest that practitioners design nutrition programs that make use of social learning, since both communities of practice and existing social networks facilitate experimentation and learning that alter practice elements and their configuration (O'Neill et al., 2019; Shove et al., 2012). Change agents such as farmers, CHWs, and interns who are active "carriers" (Shove \& Pantzar, 2005) or hosts of particular social practices are instrumental in recruiting more people to adopt desired practices. We found that encounters with people who were already growing, purchasing, cooking, and eating local food activated new forms of competence and meaning-making in relation to food, agriculture, health, and community. Participants were inspired to try new varieties of produce and cook new recipes because of their relationship to local food producers and suppliers. Forming relationships between participants and carriers of alternative food practices-particularly in the case of health clinic patients and local farmers in Portland-also helped alter how practices interlock by expanding the meanings that participants attached to locally produced food as a part of nature.

The Odyssey-SFUW partnership in Madison and the CSAP4H program in Portland created what O'Neill et al. (2019) refer to as a "fracture": a critical moment in which social practices become more open to change at the microscale of individuals, households, and small communities of practice. The programs created space for participants to alter their existing food practices by combining materials, competences, and meanings in new ways. However, community-based nutrition programs are inherently limited in terms of their ability to elicit transformative meso- and macro-scale change unless there is a parallel effort to address the structural constraints that make it difficult for lowincome individuals to continue to reproduce these practices after the program is over. When these programs end, and the financial subsidies they provide are terminated, the alternative food practices they promoted may be "disintegrated" (Maller \& Strengers, 2013) and certain practices (e.g. eating organic food or participating in a CSA) may become ex-practices. Such disintegration is a potential source of frustration and disempowerment for program participants when competences and meanings have been altered, but the materials required to perform alternative food practices are no longer financially accessible.

Grant funding for the Portland CSAP4H 
fluctuates from year to year, creating uncertainty for program participants and the farmers who supply the CSA. However, since the program began in 2015, the program has been continuously funded and participants, who pay US $\$ 5$ per week for a CSA share valued at US $\$ 27$, have been able to re-enroll every year. Madison participants, on the other hand, were not eligible to continue receiving their food exploration deliveries after the OdysseySFUW grant-funded partnership ended. Some Madison participants reported that they plan to continue incorporating materials, competences, and meanings into their home-cooking practices, thereby making the new practices conform to their existing income-constrained food provisioning routines. However, most Madison participants reported that they would be unlikely to continue consuming organic and locally grown food because of the price premium attached to such foods. Without adequate financial resources to purchase more costly items, low-income carriers of alternative food practices may have no choice but to substitute cheaper foods into their diets, despite having acquired new food-related competences and meanings through their participation in communitybased nutrition programming.

The potential disintegration of new cooking and dietary practices speaks to an important limitation of short-term nutrition programs and the need to address the structural issues of poverty and food insecurity. Raising wages and lifting low-income families out of poverty would have a profound effect on reducing dietary disparities in the U.S. by increasing their ability to afford healthy foods
(Hough \& Sosa, 2015; Otero, Pechlaner, Liberman, \& Gürcan, 2015). Achieving such a macrolevel economic shift is a long-term organizing challenge for the U.S. food movement and one that will require strong academic-activist partnerships (Levkoe et al., 2016). In the meantime, our study provides useful insight into how community-based nutrition programs support the adoption of alternative food practices and demonstrates why the subsidies for healthy, local food provided by these programs should be part of a broader strategy to address poverty and food insecurity.

\section{Acknowledgments}

We extend gratitude to the farms and health centers involved in the 2018 Portland CSA Partnerships for Health program: 47th Avenue Farm, Full Cellar Farm, Mudbone Grown, Schoolyard Farms, Zenger Farm, La Clinica de Buena Salud, Kaiser Permanente Rockwood Medical Office, OHSU Family Medicine at Richmond, Outside In, Wallace Medical Concern, and Multnomah County's Mid County, North Portland, and Southeast Health Centers. We also thank Taissa Achar-Winkels and Aurora Silva-Ramirez for their Spanish facilitation and translation support. We thank Dr. Betty Izumi of Portland State University for her contributions to CSA Partnerships for Health and for her input on this manuscript. We also wish to thank UWMadison campus and community partners, the UW Odyssey Project and Slow Food UW-Madison, for their vision and creation of this community of practice and community-based research project.

\section{References}

Alkon, A. H. (2012). Black, white, and green: Farmers markets, race, and the green economy. Athens: University of Georgia Press.

Andreatta, S., Rhyne, M., \& Dery, N. (2008). Lessons learned from advocating CSAs for low-income and food insecure households. Journal of Rural Social Sciences, 23(1), 116-148. https://egrove.olemiss.edu/jrss/vol23/iss1/6

Balvanz, P., Barlow, M. L., Lewis, L. M., Samuel, K., Owens, W., Parker, D. L., . . Ammerman, A. (2011). "The next generation, that's why we continue to do what we do": African American farmers speak about experiences with land ownership and loss in North Carolina. Journal of Agriculture, Food Systems, and Community Development, 1(3), 67-88. https://doi.org/10.5304/jafscd.2011.013.011

Bryce, R., Guajardo, C., Ilarraza, D., Milgrom, N., Pike, D., Savoie, K., Valbuena, F., \& Miller-Matero, L. R. (2017). Participation in a farmers' market fruit and vegetable prescription program at a federally qualified health center improves hemoglobin A1C in low income uncontrolled diabetics. Preventive Medicine Reports, 7, 176-179. https://doi.org/10.1016/j.pmedr.2017.06.006 
Castellanos, D. C., Keller, J., \& Majchrzak, E. (2016). Exploring the connection between community food security initiatives and social-cognitive factors on dietary intake. Journal of Agriculture, Food Systems, and Community Development, 7(1), 21-31. https://doi.org/10.5304/jafscd.2016.071.006

Clark-Barol, M., Gaddis, J., \& Barrett, C. (2021). Food agency in low-income households: A qualitative study of the structural and individual factors impacting participants in a community-based nutrition program. Appetite, 158(1), 105013. https://doi.org/10.1016/j.appet.2020.105013

Cohen, N., \& Derryck, D. (2011). Corbin Hill Road farm share: A hybrid food value chain in practice. Journal of Agriculture, Food Systems, and Community Development, 1(4), 85-100. https://doi.org/10.5304/jafscd.2011.014.011

Cummins, S., Flint, E., \& Matthews, S. A. (2014). New neighborhood grocery store increased awareness of food access but did not alter dietary habits or obesity. Health Affairs, 33(2), 283-291. https://doi.org/10.1377/hlthaff.2013.0512

Delormier, T., Frohlich, K. L., \& Potvin, L. (2009). Food and eating as social practice-understanding eating patterns as social phenomena and implications for public health. Sociology of Health \& Illness, 31(2), 215-228. https://doi.org/10.1111/j.1467-9566.2008.01128.x

Devaney, L., \& Davies, A. R. (2017). Disrupting household food consumption through experimental HomeLabs: Outcomes, connections, contexts. Journal of Consumer Culture, 17(3), 823-844. https://doi.org/10.1177/1469540516631153

Farmer, J. R., Babb, A., Minard, S., \& Veldman, M. (2019). Accessing local foods: Households using SNAP double bucks and financial incentives at a Midwestern farmers market. Journal of Agriculture, Food Systems, and Community Development, 8(4), 153-178. https://doi.org/10.5304/jafscd.2019.084.005

Fonte, M. (2013). Food consumption as social practice: Solidarity purchasing groups in Rome, Italy. Journal of Rural Studies, 32, 230-239. https://doi.org/10.1016/j.jrurstud.2013.07.003

Forbes, C. B., \& Harmon, A. H. (2008). Buying into community supported agriculture: Strategies for overcoming income barriers. Journal of Hunger and Environmental Nutrition, 2(2-3), 65-79. https://doi.org/10.1080/19320240801891479

Guthman, J. (2008). Bringing good food to others: Investigating the subjects of alternative food practice. Cultural Geographies, 15(4), 431-447. https://doi.org/10.1177/1474474008094315

Guthman, J. (2011). "If they only knew": The unbearable whiteness of alternative food. In A. H. Alkon \& J. Agyeman (Eds.), Cultivating food justice: Race, class, and sustainability (pp. 263-282). Cambridge: Massachusetts Institute of Technology Press.

Hough, G., \& Sosa, M. (2015). Food choice in low income populations-A review. Food Quality and Preference, 40(B), 334-342. https://doi.org/10.1016/i.foodqual.2014.05.003

Izumi, B. T., Martin, A., Garvin, T., Higgins Tejera, C., Ness, S., Pranian, K., \& Lubowicki, L. (in press). CSA Partnerships for Health: Outcome evaluation results from a subsidized community supported agriculture program to connect safety net clinic patients with farms to improve dietary behaviors, food security, and overall health. Translational Behavioral Medicine.

Jurkowski, J. M., \& Paul-Ward, A. (2007). Photovoice with vulnerable populations: Addressing disparities in health promotion among people with intellectual disabilities. Health Promotion Practice, 8(4), 358-365. https://doi.org/10.1177/1524839906292181

Kendall, H., Brennan, M., Seal, C., Ladha, C., \& Kuznesof, S. (2016). Behind the kitchen door: A novel mixed method approach for exploring the food provisioning practices of the older consumer. Food Quality and Preference, 53, 105116. https://doi.org/10.1016/j.foodqual.2016.06.005

Landis, B., Smith, T. E., Lairson, M., Mckay, K., Nelson, H., \& O’Briant, J. (2010). Community-supported agriculture in the Research Triangle region of North Carolina: Demographics and effects of membership on household food supply and diet. Journal of Hunger and Environmental Nutrition, 5(1), 70-84. https://doi.org/10.1080/19320240903574403

Levkoe, C. Z., McClintock, N., Minkoff-Zern, L.-A., Coplen, A. K., Gaddis, J., Lo, J., . . Weiler, A. M. (2016). Forging links between food chain labor activists and academics. Journal of Agriculture, Food Systems, and Community Development, 6(2), 129-142. https://doi.org/10.5304/jafscd.2016.062.009 
Livingood, W., Monticalvo, D., Bernhardt, J., Wells, K. T., Harris, T., Kee, K., . .Woodhouse, L. D. (2017). Engaging adolescents through participatory and qualitative research methods to develop a digital communication intervention to reduce adolescent obesity. Health Education \& Behavior, 44(4), 570-580. https://doi.org/10.1177/1090198116677216

Maller, C. J. (2015). Understanding health through social practices: Performance and materiality in everyday life. Sociology of Health \& Illness, 37(1), 52-66. https://doi.org/10.1111/1467-9566.12178

Maller, C. J., \& Strengers, Y. (2013). The global migration of everyday life: Investigating the practice memories of Australian migrants. Geoforum, 44, 243-252. https://doi.org/10.1016/j.geoforum.2012.09.002

Mann, J., Miller, S., O’Hara, J., Goddeeris, L., Pirog, R., \& Trumbull, E. (2018). Healthy food incentive impacts on direct-to-consumer sales: A Michigan example. Journal of Agriculture, Food Systems, and Community Development, 8(1), 97112. https://doi.org/10.5304/jafscd.2018.081.006

Martin, A., Coplen, A., Lubowicki, L., \& Izumi, B. T. (2020). A photovoice inquiry into the impacts of a subsidized CS A program on participants' health. Manuscript submitted for publication.

McKee, E. (2018). "It's the Amazon world": Small-scale farmers on an entrepreneurial treadmill. Culture, Agriculture, Food and Environment, 40(1), 65-69. https://doi.org/10.1111/cuag.12107

McGuirt, J. T., Jilcott Pitts, S. B., Seguin, R. A., Bentley, M., DeMarco, M., \& Ammerman, A. S. (2018). Perspectives on a local food access and nutrition education program from Cooperative Extension nutrition educators. Journal of Agriculture, Food Systems, and Community Development, 8(3), 105-122. https://doi.org/10.5304/jafscd.2018.083.002

McGuirt, J., Sitaker, M., Jilcott Pitts, S. B., Ammerman, A. S., Kolodinsky, J., \& Seguin-Fowler, R. A. (2019). A mixedmethods examination of the geospatial and sociodemographic context of a direct-to-consumer food system innovation. Journal of Agriculture, Food Systems, and Community Development, 9(Suppl. 1), 159-177. https://doi.org/10.5304/jafscd.2019.091.038

McMorrow, S., \& Saksena, J. (2017). Voices and views of Congolese refugee women: A qualitative exploration to inform health promotion and reduce inequities. Health Education \& Behavior, 44(5), 769-780. https://doi.org/10.1177/1090198117726572

Morgan C. B. (2020). Expanding food agency theory and measurement with mixed methods: A study from Philadelphia. Journal of Agriculture, Food Systems, and Community Development, 9(4), 229-244. https://doi.org/10.5304/jafscd.2020.094.016

Mylan, J., \& Southerton, D. (2018). The social ordering of an everyday practice: The case of laundry. Sociology, 52(6), 1134-1151. https://doi.org/10.1177\%2F0038038517722932

Oberholtzer, L., Dimitri, C., \& Schumacher, G. (2012). Linking farmers, healthy foods, and underserved consumers: Exploring the impact of nutrition incentive programs on farmers and farmers' markets. Journal of Agriculture, Food Systems, and Community Development, 2(4), 63-77. https://doi.org/10.5304/jafscd.2012.024.002

O’Neill, K. J., Clear, A. K., Friday, A., \& Hazas, M. (2019). 'Fractures' in food practices: Exploring transitions towards sustainable food. Agriculture and Human Values, 36(2), 225-239. https://doi.org/10.1007/s10460-019-09913-6

Otero, G., Pechlaner, G., Liberman, G., \& Gürcan, E. (2015). The neoliberal diet and inequality in the United States. Social Science \& Medicine, 142, 47-55. https://doi.org/10.1016/j.socscimed.2015.08.005

Pine, A. M., \& de Souza, R. (2013). Including the voices of communities in food insecurity research: An empowermentbased agenda for food scholarship. Journal of Agriculture, Food Systems, and Community Development, 3(4), 71-79. https://doi.org/10.5304/jafscd.2013.034.007

Porter, C. (2018). Triple-rigorous storytelling: A PI's reflections on devising case study methods with five communitybased food justice organizations. Journal of Agriculture, Food Systems, and Community Development, 8(Suppl. 1), 37-61. https://doi.org/10.5304/jafscd.2018.08A.008

Quandt, S. A., Dupuis, J., Fish, C., and D'Agostino, R. B. (2013). Feasibility of using a community-supported agriculture program to improve fruit and vegetable inventories and consumption in an underresourced urban community. Preventing Chronic Disease, 10, E136. https://dx.doi.org/10.5888\%2Fpcd10.130053

Reckwitz, A. (2002). Toward a theory of social practices: A development in culturalist theorizing. European Journal of Social Theory, 5(2), 243-263. https://doi.org/10.1177\%2F13684310222225432 
Ridberg, R. A., Bell, J. F., Merritt, K. E., Harris, D. M., Young, H. M., \& Tancredi, D. J. (2019). A pediatric fruit and vegetable prescription program increases food security in low-income households. Journal of Nutrition Education and Behavior, 51(2), P224-P230. https://doi.org/10.1016/j.jneb.2018.08.003

Shove, E., \& Pantzar, M. (2005). Consumers, producers and practices: Understanding the invention and reinvention of Nordic walking. Journal of Consumer Culture, 5(1), 43-64. https://doi.org/10.1177\%2F1469540505049846

Shove, E., Pantzar, M., \& Watson, M. (2012). The dynamics of social practice: Everyday life and how it changes. London: SAGE.

Slocum, R. (2006). Whiteness, space and alternative food practice. Geoforum, 38(3), 520-533. http://doi.org/10.1016/j.geoforum.2006.10.006

Southerton, D., Chappells, H., \& van Vliet, B. (2004). Sustainable consumption: The implications of changing infrastructures of provision. Cheltenham, UK: Edward Elgar.

Southerton, D., Díaz-Méndez, C., \& Warde, A. (2012). Behavioral change and the temporal ordering of eating practices: A UK-Spain comparison. International Journal of Sociology of Agriculture and Food, 19(1), 19-36.

Spaargaren, G. (2003). Sustainable consumption: A theoretical and environmental policy perspective. Society and Natural Resources, 16(8), 687-701. https://doi.org/10.1080/08941920309192

Spaargaren, G., Oosterveer, P., \& Loeber, A. (Eds.). (2013). Food practices in transition: Changing food consumption, retail and production in the age of reflexive modernity. New York, NY \& Abingdon, UK: Routledge.

Torkkeli, K., Mäkelä, J., \& Niva, M. (2020). Elements of practice in the analysis of auto-ethnographical cooking videos. Journal of Consumer Culture, 20(4), 543-562. https://doi.org/10.1177/1469540518764248

Trubek, A. B., Carabello, M., Morgan, C., \& Lahne, J. (2017). Empowered to cook: The crucial role of 'food agency' in making meals. Appetite, 116, 297-305. https://doi.org/10.1016/j.appet.2017.05.017

Tucker, C. A. (2019). Food practices of environmentally conscientious New Zealanders. Environmental Sociology, 5(1), 8292. https://doi.org/10.1080/23251042.2018.1495038

Trotter, G. (2018, October 20). Fewer consumers opting for that weekly box of veggies, so local farmers are struggling to survive. Chicago Tribune. Retrieved from https://www.chicagotribune.com/business/ct-biz-illinois-farmers-struggling-20180921-story.html

Twine, R. (2015). Understanding snacking through a practice theory lens. Sociology of Health \& Illness, 37(8), 1270-1284. https://doi.org/10.1111/1467-9566.12310

Vasquez A., Sherwood N. E., Larson N., \& Story, M. (2017) Community-supported agriculture as a dietary and health improvement strategy: A narrative review. Journal of the Academy of Nutrition and Dietetics, 117(1), P83-P94. https://doi.org/10.1016/j.jand.2016.09.029

Vernon, R. V. (2015). A Native perspective: Food is more than consumption. Journal of Agriculture, Food Systems, and Community Development, 5(4), 137-142. https://doi.org/10.5304/jafscd.2015.054.024

Wang, C. C. (1999). Photovoice: A participatory action research strategy applied to women's health. Journal of Women's Health, 8(2), 185-192. https://doi.org/10.1089/jwh.1999.8.185

Wang, C. C., Yi, W. K., Tao, Z. W., \& Carovano, K. (1998). Photovoice as a participatory health promotion strategy. Health Promotion International, 13(1), 75-86. https://doi.org/10.1093/heapro/13.1.75

White, M. J., Jilcott Pitts, S. B., McGuirt, J. T., Hanson, K. L., Morgan, E. H., Kolodinsky, J., . . Seguin, R. A. (2018). The perceived influence of cost-offset community-supported agriculture on food access among low-income families. Public Health Nutrition, 21(15), 2866-2874. https://doi.org/10.1017/S1368980018001751

Wilkins, J. L., Farrell, T. J., \& Rangarajan, A. (2015). Linking vegetable preferences, health and local food systems through community-supported agriculture. Public Health Nutrition, 18(13), 2392-2401. https://doi.org/10.1017/S1368980015000713

Woodruff, R. C., Arriola, K. J., Powell-Threets, K., Nuri, K. R., Hunter, C., \& Kegler, M. C. (2018). Urban farmers markets as a strategy to increase access to and consumption of fresh vegetables among SNAP and non-SNAP participants: Results from an evaluation. Journal of Agriculture, Food Systems, and Community Development, 8(2), 93-105. https://doi.org/10.5304/jafscd.2018.082.013

Woodsum, G. M. (2018). The cost of community-based action research: Examining research access and implementation through the food dignity project community support package. Journal of Agriculture, Food Systems, and Community Development, 8(Suppl. 1), 83-99. https://doi.org/10.5304/jafscd.2018.08A.021 